\title{
As relações familiares com adolescentes usuários de substâncias psicoativas: percepção dos pais*
}

Sonia Regina Zerbetto ${ }^{1}$,

Bianca Oliveira Ruiz², Sueli Aparecida Frari Galera ${ }^{3}$, Ana Carolina Guidorizzi Zanetti ${ }^{4}$

\section{RESUMO}

O objetivo deste estudo consiste em discutir a experiência das famílias que cuidam de adolescentes consumidores de substâncias psicoativas, no âmbito de seu funcionamento. Estudo qualitativo, descritivo, tendo como participantes da pesquisa os genitores de adolescentes consumidores de drogas, de um Centro de Atenção Psicossocial-Álcool e Drogas do interior paulista. Foram realizadas entrevistas semiestruturadas e os dados foram analisados pela técnica de análise de conteúdo, categorial temática. Os resultados apontam que estes genitores apresentam dificuldade de estabelecer diálogo assertivo com seus filhos e filhas, em desenvolver seu papel hierárquico e de estabelecer limites ao adolescente. Tais situações geram sentimentos ambivalentes e emoções negativas que os mobilizam a buscar apoio no âmbito familiar, informacional, religioso e instrumental. Conclui-se que o cuidado deve envolver o adolescente que consome drogas e sua família, considerando os aspectos interacionais, organizacionais e comunicacional do coletivo familiar.

Descritores: Relações Familiares; Família; Adolescente; Transtornos Relacionados ao Uso de Substâncias; Enfermagem Psiquiátrica.

\footnotetext{
* Esta pesquisa consiste em iniciação cientifica com apoio da Fundação de Amparo à Pesquisa do Estado de São Paulo.

${ }^{1}$ Enfermeira, Doutora em Enfermagem Psiquiátrica. Professora Adjunta da Universidade Federal de São Carlos. São Carlos, SP, Brasil. E-mail: szerbetto@ufscar.br.

2 Enfermeira, Mestre em Enfermagem. São Carlos, SP, Brasil. E-mail: biancaruiz.enf@gmail.com.

${ }^{3}$ Enfermeira, Doutora em Enfermagem. Professora Associada da Escola de Enfermagem de Ribeirão Preto da Universidade de São Paulo. Ribeirão Preto, SP, Brasil. E-mail: sugalera@eerp.usp.br.

${ }^{4}$ Enfermeira, Doutora em Enfermagem Psiquiátrica. Professa Doutora da Escola de Enfermagem de Ribeirão Preto da Universidade de São Paulo. Ribeirão Preto, SP, Brasil. E-mail: carolzan@eerp.usp.br.
}

\section{Como citar esse artigo:}

Zerbetto SR, Ruiz BO, Galera SAF, Zanetti ACG. As relações familiares com adolescentes usuários de substâncias psicoativas: percepção dos pais. Rev. Eletr. Enf. [Internet]. 2018 [acesso em: ;20:v20a16.

Disponível em: https://doi.org/10.5216/ree.v20.46353. 


\section{INTRODUÇÃO}

A adolescência é uma fase transacional do ciclo vital entre a infância e a fase adulta, permeada por transformações biopsicossociais ${ }^{(1-2)}$. Esta etapa é considerada de maior vulnerabilidade motivacional para o início experimental de bebida alcoólica ${ }^{(3)}$ e outras drogas pelos adolescentes ${ }^{(4)}$, por serem consideradas como facilitadoras da desinibição e sociabilidade ${ }^{(3)}$.

Estudos identificaram alta prevalência de consumo de drogas entre adolescentes ${ }^{(5-6)}$, sendo que este consumo pode desencadear problemas nas interações e comunicações familiares ${ }^{(5,7)}$, tais como, o adolescente mentir para os familiares, agredir fisicamente o membro familiar e isolar-se do convívio da família ${ }^{(7)}$.

As investigações que exploraram o contexto familiar de adolescentes consumidores de substâncias psicoativas (SPAs) aprofundaram pouco o conhecimento sobre o impacto do uso destas substâncias na dinâmica e funcionamento familiar, e a reação da família diante de tal problemática ${ }^{(5-7)}$. Assim, entender a maneira como os familiares se (re)organizam em relação aos papéis hierárquicos, à comunicação e expressão de suas emoções para cuidarem deste adolescente pode possibilitar tal aprofundamento, e fornecer subsídios para a efetivação de medidas de prevenção do uso de SPAs e dos inúmeros problemas acarretados por seu consumo.

Na perspectiva da teoria sistêmica estrutural, considera-se que o funcionamento familiar envolve processos relacionais entre os membros da família e a maneira como estes desempenham as suas funções ${ }^{(8)}$. Compreender tal processo é fundamental para ajudar a família a cumprir seu papel de cuidador. Assim, este estudo teve como objetivo discutir a experiência das famílias que cuidam de adolescentes consumidores de substâncias psicoativas, no âmbito de seu funcionamento.

\section{MÉTODO}

Estudo qualitativo, descritivo, tendo como referencial teórico a perspectiva familiar sistêmica estrutural de Salvador Minuchin ${ }^{(9)}$, que fundamentou a coleta e análise de dados.

O modelo sistêmico estrutural compreende a família como sistema aberto, cujos membros estão em constante interação e assumem papéis e funções para manter a estabilidade dinâmica deste sistema frente às influências internas e externas ${ }^{(9)}$. Nesta perspectiva, compreende-se a dependência química como sintoma que exerce uma função na dinâmica familiar, regula este sistema e denuncia suas dificuldades ${ }^{(10)}$. Portanto, tal situação adversa afeta o coletivo familiar, que é afetado pelo processo de adoecimento de um de seus membros, e a família tenta se (re)organizar para cuidar de seu parente.

No processo de busca da estabilidade funcional, a família tenta restabelecer as hierarquias e formular limites claros nas relações intrafamiliares; definir papéis e funções de seus componentes, estabelecer ou dissolver alianças ou triangulações, expressar sentimentos e interações emocionais no contexto familiar e buscar soluções para os problemas ${ }^{(9)}$.

A pesquisa foi realizada no período de julho/2013 e agosto/2014, em quatro famílias, com genitores de adolescentes consumidores de drogas cadastrados e em tratamento em Centro de Atenção Psicossocial - álcool e drogas (CAPS ad) do interior do Estado de São Paulo/Brasil. Dentre os participantes, somente uma família era constituída de pai e mãe, enquanto nas outras três, apenas a mãe era o membro responsável. 
A equipe de saúde do respectivo serviço identificou o total de sete famílias, mas três não foram encontradas após vários contatos telefônicos e visitas domiciliares. O critério de inclusão consistiu em: pais biológicos ou não de adolescentes, maiores de 18 anos, em tratamento e que conviviam com o adolescente pelo menos duas vezes por semana. Os critérios de exclusão foram: pais que alegaram uso abusivo ou dependente de SPAs. A maioria dos pais dos adolescentes possuía histórico de consumo de múltiplas drogas, fator que reduziu o número dos participantes da pesquisa. Entretanto, foram entrevistadas todas as famílias que respeitavam os critérios de inclusão.

Para a coleta de dados, foi realizada pelas pesquisadoras uma entrevista semiestruturada com cada família, no domicílio ou CAPS ad. As entrevistas foram gravadas por áudio e consistiram na caracterização dos participantes quanto aos dados de identificação pessoal e profissional, configuração familiar e uma questão norteadora: “Como é para você(s) cuidar(em) de seu filho(a) que faz uso de drogas?”. Realizou-se, também, genograma e ecomapa de cada família, para captar a estrutura familiar e sua dinâmica relacional, bem como as relações entre família e comunidade ${ }^{(11)}$, apreendendo a rede de apoio e suporte social.

Para o processo analítico dos dados, foi utilizada a técnica de análise de conteúdo, categorial temática de Bardin $^{(12)}$. As entrevistas foram transcritas, lidas diversas vezes em profundidade. As unidades de análise consistiram em recortes textuais codificados alfanumericamente, em modo de trilhas, com abordagem sobre funcionamento da família ao cuidar do filho ou filha, tais como: papéis hierárquicos, processos relacionais e modo de comunicação, sentimentos emergentes e estratégias de enfrentamento da situação. Os recortes foram agregados de acordo com os temas correlatos, mesmo conteúdo semântico, cuja presença recorrente de aparição ou relevância implícita poderia significar algo para o objetivo analítico escolhido(12). Os temas foram discutidos pelas autoras e o consenso foi alcançado sobre a codificação para reduzir o viés. Estas unidades foram reagrupadas tematicamente em categorias.

Para o tratamento dos resultados, realizaram-se inferências e interpretação respaldadas no conceito teórico sistêmico estrutural.

As falas foram identificadas com as iniciais EF (Entrevista de Família), seguidas pelo número sequencial das entrevistas e iniciais de parentesco (M-Mãe e P-Pai), bem como pela sequência numeral da fala, como por exemplo, EF1-M3 (Entrevista de Família número 1, referente à fala de número 3 da Mãe).

A análise de dados proporcionou o surgimento de três categorias: Enfrentando dificuldades na comunicação intrafamiliar; Convivendo com sentimentos ambivalentes; Buscando apoio familiar, da comunidade e religioso.

O estudo respeitou os aspectos éticos da Resolução 466/12 e foi aprovado pelo Comitê de Ética em Pesquisa em Seres Humanos, conforme parecer no 219.412/2013 de 14/03/2013. Os participantes assinaram o Termo de Consentimento Livre e Esclarecido.

\section{RESULTADOS}

Quanto à caracterização das famílias, duas delas tinham configuração nuclear (pai, mãe e filhos), uma monoparental (mãe e filhos) e outra de família reconstruída (filhos, mãe e um novo companheiro, sem ser o pai 
biológico dos adolescentes). A faixa etária dos pais variou de 35 a 52 anos. No que se refere à ocupação, uma mãe era "do lar", outra faxineira, duas empregadas domésticas e o membro paterno era catador de material reciclável.

A mãe constituiu o membro predominante nas entrevistas, corroborando a literatura que aponta ser a figura materna o membro mais participante do tratamento ${ }^{(13)}$.

A seguir são apresentadas as categorias obtidas das análises.

\section{Enfrentando dificuldades na comunicação intrafamiliar}

Esta categoria apontou dificuldade de comunicação entre pais e seus filhos, justificada pela ausência de escuta entre ambos e tomada de decisão dos adolescentes, sem a participação dos genitores. Os pais tentaram assumir o papel hierárquico de autoridade no estabelecimento de limites em relação aos filhos e no controle da situação, que na percepção deles foi inadequada.

Ele [adolescente] não escuta a gente, ele quer fazer tudo do jeito dele. Então, fica mais difícil (EF3-M1).

Tem que ser do jeito que a [nome da adolescente] quer. Ela quer na hora, o que interessa ela é o que vem na cabeça dela. [...] Tem quem manda na minha casa. Ela acha o que? Enquanto eu tô ali, a casa é minha e quem tem autoridade sou eu (EF4-P9).

A comunicação ineficaz tornou-se evidente quando os pais descobriram o consumo das drogas e não conseguiram dialogar com os filhos sobre o assunto. Tais impedimentos geraram ressonâncias na comunicação emocional, dificultando que ambos expressassem e demonstrassem sentimentos de afeto, atenção, carinho. Tal fato, também desencadeou distanciamento físico e afetivo entre eles.

Até porque esse lança perfume é o que ela [adolescente] usa. Já peguei um vidro na minha casa. Porque ela não deixa nada a gente ver. E ela falou: "Ah, você não me dá atenção", mas ela não deixa chegar nela, ela não deixa você fazer carinho nela. É uma pessoa que quer ficar sozinha, não se abre com a gente. [...] Ela [adolescente] guarda tudo para ela, não fala nada para gente (EF4-M8).

A dificuldade de diálogo pode desencadear o distanciamento do filho em relação à família de origem e a aproximação de amizades externas para estabelecimento de alianças.

Agora, ela [adolescente] não quer se juntar a nós [família]. Ela dá preferência lá fora; as amigas são tudo mais importante. Por mais que você esclareça... "você vai ter dois ou três dias de apoio lá fora" (EF4-P12).

\section{Convivendo com sentimentos ambivalentes}

Esta categoria salientou os sentimentos ambivalentes e emoções negativas expressos pelos genitores no processo relacional entre os filhos e a droga.

Uma das mães participantes deste estudo vivenciou sentimentos simultâneos de culpa e não culpa ao refletir sobre as possíveis causas do envolvimento do filho com as drogas, pois relacionou tal atitude com o modo de criação e educação ofertado ao adolescente. Ao mesmo tempo em que se questionou sobre possíveis erros na maneira de educá-lo, acreditou que nem ela e nem o esposo foram responsáveis pelas atitudes do filho, quando comparou as atitudes deste com as da filha mais velha. 
Têm horas que a gente fala: "Não, a gente não errou [...] nós não fizemos nada de errado, porque se fosse culpa nossa, a outra filha também teria ido pelo mesmo caminho" (EF1-M14).

O relato de outra mãe apontou sentimento ambivalente de perdoar ou não perdoar o filho usuário de drogas, durante a tomada de decisão sobre retomar ou não o contato com ele, que se encontrava em uma instituição de reabilitação para adolescente infrator. Para ela, tal processo decisório requereu um intenso esforço emocional e gerou grande sofrimento.

Não sei se eu fiquei dois meses ou um mês e pouco sem ir lá [instituição de reabilitação para adolescente infrator] ver o [nome do adolescente]. Não fui. Sabe, seu coração pedia para você não ir. Eu chorava e chorava e chorava. Aí, um dia, eu falei: "eu vou lá ver o [nome do adolescente]" [...] Deus tá pondo no meu coração para mim ir lá e perdoar ele, conversar com ele. Eu falei: "'eu não vou perdoar porque quem perdoa é Deus, não é? Eu não sou Deus para perdoar, eu vou conversar com ele" (EF2-M17).

Os sentimentos de medo, frustração, fracasso e impotência foram destacados pelos genitores e relacionados às recaídas vivenciadas pelo adolescente e o desejo dos pais de evitá-las. Na percepção dos pais, a perda representou um sentimento relacionado ao envolvimento do filho com as drogas. O medo foi associado à violência e morte, contextos dos quais o adolescente pode ser vítima, gerando sentimentos de insegurança nos pais.

Têm horas, quando ele [adolescente] chega, que você percebe que ele usou. Nossa! Dá uma sensação de fracasso, dá uma sensação de frustração, de perda (EF1-M18).

Agora, é o medo que a gente tem. Que hoje em dia, por causa de uma porcaria de uma pedra, um cigarrinho de maconha, hoje tá dando facada, tá tirando a vida assim, de uma hora para outra (EF4-P17).

A descoberta das drogas pelos pais gerou emoções negativas, atitudes de agressividade física e perplexidade.

Eu descobri quando ele [adolescente] foi em casa [...] fui ol har a mochila e eu achei a droga. Bati nele, esfreguei a droga na cara dele, tudo. [...] Eu peguei a maconha. [...] Ah, eu entrei em choque. [...] Eu chorei, eu fiquei nervosa. Eu fiquei dois dias sem dormir (EF2-M1).

\section{Buscando apoio familiar, da comunidade e religioso}

Esta categoria explorou os recursos utilizados pelos genitores na tentativa de solucionar os problemas vivenciados.

Para os genitores de uma mesma família, a coesão entre eles os fortaleceu para ajudarem a adolescente.

A gente [casal] se uniu [...] porque é um puxar o outro, porque se um cair vai cair todos. A gente procurou se fortalecer mais pra poder ajudar ela [adolescente], né? Porque sozinha também ela não vai sair disso (EF4-M5).

Nós nos unimos mais forte ainda, pra não quebrar (EF4-P11).

O grupo de mútua ajuda foi apontado como suporte informacional, em que a família obteve orientações de como lidar com o adolescente, impor-lhe limites de maneira firme e afetiva ao mesmo tempo. 
Lá no Amor Exigente ensinaram. A gente tá ouvindo as palestras [...] eles falam que ao mesmo tempo em que a gente vai chamar a atenção, você vai corrigir, você vai falar não, mas com a outra mão, você vai afagar, você vai agradar (EF1M19).

As famílias identificaram o apoio religioso na crença de uma força advinda de Deus que as auxiliou a persistir e lutar. A motivação e o papel de supervisora de seus filhos foram relacionados à responsabilidade destas mães por tê-los gerado. Os familiares frequentaram a igreja e pediram por intermédio de oração, a proteção para seus filhos e ao reconhecerem seus limites humanos, delegaram a Deus a responsabilidade da intervenção.

Não sei não, apareceu uma força. A gente tem que lutar, né? [...] Eu pus ele [adolescente] no mundo. Foi depois que eu comecei a ir pra igreja [...] hora de dormir, eu rezo bastante, eu peço para o anjo da guarda dos dois [filhos] (EF2-M13). É o que faço, pedir para o Pai celestial, né? E pôr na mão Dele, porque o que nós já fizemos, não sabemos mais o que fazer. Só Deus (EF4-M1).

As famílias reconheceram como apoio, o auxílio financeiro ofertado por parentes e membros da igreja, a qual foi reconhecida como instituição acolhedora e assistencialista.

Que nem minha sogra. Eu ajudo ela. Eu não tô trabalhando.[...] esse mês ela vai pagar o meu aluguel. Eu vou lá, lavo uma louça, ajudo ela a montar uma marmita. [...] Agora eu tô indo fazer faxina em [nome de uma cidade do interior paulista]. Uma ajuda a outra, né (EF2-M14)?

É igreja. Teve uma época que a gente passou bem apertado, quem socorreu foi a igreja. "Olha, a gente não tem condição de comprar esse remédio", eles pegam a nossa receita, eles compram [...] Sempre nos ajudaram, nos acolheram (EF4M14).

Outras instituições reconhecidas como suporte consistiram em equipamento de saúde, como o CAPS ad.

É o CAPS, né? A ajuda do CAPS, né (EF3-M7)?

\section{DISCUSSÃO}

O presente estudo apontou que a problemática da dependência de substâncias psicoativas impacta o funcionamento das famílias, desencadeia dificuldades no processo de comunicação intrafamiliar, convivência dos genitores com sentimentos ambivalentes e emoções negativas. Na tentativa de superar e enfrentar tais dificuldades, os genitores buscaram apoio no âmbito familiar, informacional, religioso e instrumental.

Os pais envolvidos neste estudo reconheceram a dificuldade de estabelecer diálogo assertivo com os filhos e desenvolver um papel hierárquico. Percebeu-se que a justificativa para tal dificuldade relacionou-se ao comportamento inadequado e de confronto do adolescente para com os genitores. Os pais, ao tentarem gerenciar tal situação, tornaram-se autoritários, aumentando a tensão e o conflito entre eles e o adolescente. Estudos apontam que pais de adolescentes consumidores de SPAs vivenciaram situações de comportamentos ameaçadores dos filhos, com envolvimento de intimidação ou agressão física e verbal(14-16).

Na perspectiva sistêmica estrutural, esta complexa interação familiar, poder hierárquico e estabelecimento de limites entre subsistemas (mãe-filho ou pai-filha) demarcam-se por fronteiras interpessoais que regulam o padrão relacional, determinam a autonomia, os papéis, regras e a hierarquia de seus integrantes ${ }^{(9)}$. 
Além disso, a fase do adolescer desencadeia transformações física, emocional e social que podem gerar conflitos internos e externos, como por exemplo, com a família. De fato, o adolescente nesta fase busca conquistar sua identidade individual e social, bem como sua autonomia e independência familiar, e em decorrência, a experimentação ou consumo de substâncias psicoativas pode ser identificado como recurso facilitador para atingir tais objetivos, conforme aponta a literatura ${ }^{(10)}$. Entretanto, neste estudo, o comportamento de confrontação entre adolescente e seus pais foi intensificado em razão dos efeitos das drogas no adolescente, como por exemplo, alteração de humor, perda da crítica e necessidade de consumir a droga, bem como pela própria fase do processo de adolescer.

Na percepção destes genitores, a dificuldade de comunicação verbal e emocional gerou distanciamento de seus filhos do ambiente familiar, que buscaram apoio externo, muitas vezes de amigos usuários de drogas. Os dados corroboram estudo ao salientar a angústia de mães e pais quando seus filhos ou filhas sumiam por dias ou da aproximação de amigos usuários de drogas ${ }^{(14)}$.

$\mathrm{Na}$ visão sistêmica estrutural, tais dificuldades relatadas pelos pais podem ser reflexos de fronteiras rígidas estabelecidas entre subsistemas, que desencadeiam padrões relacionais distantes, decorrentes de pouca comunicação verbal e não verbal. Embora tal modo de relação gere atitudes de autonomia e independência em seus membros, eles se mantêm isolados entre si, limitando a proximidade amorosa, afetiva e de proteção(9), fatores percebidos nos relatos deste estudo. Portanto, é desejável que a família construa fronteiras nítidas, permita o diálogo eficaz, determine regras flexíveis, possibilite autonomia individual e de subsistema que garanta apoio, amor e afeto entre os membros.

Infere-se que os pais participantes deste estudo, no exercício de sua parentalidade, ao desempenharem suas tarefas e papéis de líderes, conselheiros e educadores, desenvolveram práticas educativas que permearam a autoridade e autoritarismo. Tal atitude, além de gerar relações não afetivas entre subsistemas, promoveu o distanciamento com os filhos, ao exigir-Ihes apenas a obediência, conforme evidência científica ${ }^{(17)}$.

Todo este processo de vivência e enfrentamento pelas famílias deste estudo desencadeou sofrimento, sentimentos ambivalentes e emoções negativas, conforme a segunda categoria.

O relato de uma das mães, participante desta pesquisa, apontou sentimento ambivalente em assumir a responsabilidade pelo uso de drogas do filho, alegando autonegligência quanto à educação dele, corroborando estudos $^{(15-16,18)}$. Pesquisa salienta que mães de adolescentes dependentes de drogas percebem seus filhos como extensões de sua própria identidade, ou seja, o bem estar destas mães está intrinsecamente atrelado às situações de conquista ou fracasso do jovem ${ }^{(19)}$. Estudos apontam que a culpa e autoculpa dos genitores pelo uso de drogas de seus filhos são sentimentos comuns, justificados pela inabilidade parental no processo educacional dos seus filhos e filhas ${ }^{(15-16,18,20-21)}$.

Infere-se que a família não soube ou não reconheceu que o problema da dependência química tem etiologia multifatorial. Na visão sistêmica, quando surgem situações de desequilíbrio no sistema familiar, há uma tendência de os membros cobrarem a execução de funções e tarefas dos outros, emergindo reivindicações de cumplicidade familiar e mecanismos indutivos à culpa ${ }^{(9)}$ e autoculpa.

Para a mãe participante deste estudo, o ato de perdoar correlacionou-se ao sentimento cristão, que envolve amor, misericórdia e compaixão. Porém, tal ato requereu-lhe um esforço emocional muito grande 
enquanto ser humano, para despojar-se de sentimentos e julgamentos negativos, que para ela, somente um Ser Superior é possuidor de tal capacidade, conforme estudo(22).

Os genitores envolvidos neste estudo também relataram sentimentos expressos de medo, nervosismo, tristeza, frustração, fracasso e impotência.

O medo representou um dos sentimentos exteriorizados mais relacionados pelas famílias que convivem com as drogas ${ }^{(16,18)}$, principalmente por envolver incerteza em relação ao futuro e à segurança do adolescente.

Outros sentimentos expressos pelas famílias participantes deste estudo envolveram a perplexidade e emoções negativas durante a descoberta do uso de drogas por um ente familiar, corroborando a literatura ${ }^{(15,18)}$. Tais situações permitem reflexão acerca da complexa e profunda experiência da família no contexto da dependência química. Estes sentimentos contraditórios envolvem tanto o adolescente dependente como a família, deixando-os susceptíveis à situações de conflito e desgaste físico, mental e emocional, conforme relatos neste estudo.

No processo de enfrentamento da problemática das drogas, os familiares envolvidos neste estudo se mobilizaram e buscaram apoio intra e externamente ao núcleo familiar. Tal recurso pode promover a coesão familiar, compreendida como união física ou emocional entre seus membros ${ }^{(23)}$ e favorecer o funcionamento harmonioso da família e o fortalecimento dos laços afetivos entre seus membros ${ }^{(22)}$. Neste estudo, houve a união parental para auxiliar a filha adoecida e manter seus membros fortalecidos.

Na visão sistêmica estrutural, tal atitude pode ser compreendida como aliança entre subsistema conjugal no enfoque funcional; ou seja, há união do casal para se fortalecer e enfrentar tais adversidades. Entretanto, podese interpretar como triangulação negativa, isto é, devido a um conflito relacional de difícil resolução entre pai e filha ou mãe e filha, um dos membros busca uma terceira pessoa para dividir as angústias e ansiedades, aliandose a ela (por exemplo, entre cônjuges) e excluindo a terceira (adolescente adicta). Portanto, esta mobilização familiar pode se caracterizar em mecanismos de manter o sintoma, resistir à mudança e manter o funcionamento do sistema dentro do padrão costumeiro(9).

Os genitores que participaram deste estudo reconheceram outros recursos de apoio, os quais envolveram grupos de mútua ajuda, instituições de saúde e religiosa, e auxílio financeiro da igreja. A literatura aponta que os pais obtêm suporte na dimensão informativa, tais como conselhos e informações sobre a maneira de cuidar dos filhos. Na dimensão emocional, há o envolvimento de afeto, amor, empatia e respeito ofertados pela família, enquanto na dimensão instrumental, ocorre o auxílio financeiro advindo da igreja, ou disponibilização de bens e serviços disponíveis na rede de saúde. Tais fatores resultam em efeitos emocionais, comportamentais e instrumentais benéficos ao ente adoecido e/ou membro familiar, melhorando a qualidade de vida de ambos ${ }^{(22)}$. $\mathrm{O}$ apoio religioso se refere à fé em um Ser Superior que promove consolo e força para lidar com os eventos adversos da vida. A percepção de se contar com a ajuda Divina gera na pessoa amparo e conforto, conforme estudo(24).

\section{CONCLUSÃO}

Esta investigação possibilitou apreender que os pais de adolescentes que consomem substâncias psicoativas, do referido CAPS ad, apresentaram dificuldade de estabelecer diálogo assertivo com seus filhos, 
desenvolver seu papel hierárquico, bem como estabelecer limites. Tais situações geraram sentimentos ambivalentes e emoções negativas que os mobilizaram na busca por recursos internos e externos à unidade familiar.

O limite deste estudo relacionou-se à participação de quatro famílias de adolescentes, considerando que a maioria destas fazia consumo de drogas. Tal fato demonstrou a prioridade de se investir em programas de prevenção ao uso de SPAs que envolvam o adolescente e seu contexto familiar.

Este estudo contribuiu para a prática de enfermagem, subsidiando-a para o cuidado não só focado no adolescente que consome drogas, mas no sistema familiar, considerando os seus aspectos interacionais, organizacionais e comunicacionais.

\section{REFERÊNCIAS}

1. Linebarger JS, Ajayi TA, Jones BL. Adolescents and young adults with life-threatening illness: special considerations, transitions in care, and the role of pediatric palliative care. Pediatr Clin North Am [Internet]. 2014 [acesso em: 27 ago. 2018];61(4):785-96. Disponível em: https://doi.org/10.1016/j.pcl.2014.05.001.

2. Finan L, Schulz J, Gordon MS, Ohannessian CM. Parental problem drinking and adolescent externalizing behaviors: The mediating role of family functioning. J Adolesc [Internet]. 2015 [acesso em: 27 ago. 2018];43:100-10. Disponível em:

https://doi.org/10.1016/j.adolescence.2015.05.001.

3. Atanázio EA, Santos JM, Dionísio LR, Silva J, Saldanha AAW. Vulnerabilidade ao uso do álcool: um estudo com adolescentes das redes pública e privada de ensino. SMAD. Revista Eletrônica Saúde Mental Álcool e Drogas [Internet]. 2013 [acesso em: 27 ago. 2018];9(1):11-7. Disponível em: https://doi.org/10.11606/issn.1806-6976.v9i1p11-17.

4. Marcon SR, Sene JO, Oliveira JRT. Contexto familiar e uso de drogas entre adolescentes em tratamento. SMAD. Revista Eletrônica Saúde Mental Álcool e Drogas [Internet]. 2015 [acesso em: 27 ago. 2018];11(3):122-8. Disponível em:

https://doi.org/10.11606/issn.1806-6976.v11i3p122-128.

5. Rozin L, Zagonel IPS. Adolescentes que fazem uso nocivo/abusivo de álcool: percepção de risco e proteção para dependência. Rev. Eletr. Enf. [Internet]. 2013 [acesso em: 27 ago. 2018];15(3):687-95. Disponível em: https://doi.org/10.5216/ree.v15i3.19658. 6. United Nations Office on Drugs and Crime. World Drug Report 2015 (United Nations publication, Sales No. E.15.XI.6) [Internet]. Viena (AU): UNODC; 2015 [acesso em: 27 ago. 2018]. Disponível em: https://www.unodc.org/documents/wdr2015/World_Drug_Report 2015.pdf.

7. Moura NA, Monteiro ARM, Freitas RJM. Adolescentes usuários de drogas (i)lícitas e práticas de violência. Rev enferm UFPE on line [Internet]. 2016 [acesso em: 27 ago. 2018];10(5):1685-93. Disponível em:

https://periodicos.ufpe.br/revistas/revistaenfermagem/article/view/13543/16313.

8. Walsh F. Fortalecendo a resiliência familiar. 1ạ ed. São Paulo: Roca; 2005.

9. Minuchim S. Famílias: funcionamento e tratamento. 2a ed. Porto Alegre: Artes Médicas; 1990.

10. Paz FM, Colossi PM. Aspectos da dinâmica da família com dependência química. Estud. psicol. (Natal) [Internet]. 2013 [acesso em: 27 ago. 2018];18(4):551-8. Disponível em: https://doi.org/10.1590/S1413-294X2013000400002.

11. Wright LM, Leahey M. Enfermeiras e famílias: um guia para avaliação e intervenção na família. 5ạ ed. São Paulo: Roca; 2013.

12. Bardin L. Análise de conteúdo. 19ạ ed. Portugal: Edições 70; 2011.

13. Azevedo CS, Silva RS. A importância da família no tratamento do dependente químico. Encontro: Revista de Psicologia [Internet]. 2013 [acesso em: 27 ago. 2018];16(25):151-62. Disponível em:

http://www.pgsskroton.com.br/seer/index.php/renc/article/view/2439.

14. Choate PW. Adolescent alcoholism and drug addiction: the experience of parents. Behav Sci (Basel) [Internet]. 2015 [acesso em: 27 ago. 2018];5(4):461-76. Disponível em: https://doi.org/10.3390/bs5040461.

15. Groenewald C, Bhana A. "It was bad to see my [child] doing this": Mothers' experiences of living with adolescents with substance abuse problems. Int J Ment Health Addiction [Internet]. 2016 [acesso em: 27 ago. 2018];14:646-61. Disponível em: https://doi.org/10.1007/s11469-015-9605-7.

16. Asante KO, Lentoor AG. Use of crystal methamphetamine among male adolescents in Cape Town, South Africa: caregivers' experiences. Subst Abuse Treat Prev Policy [Internet]. 2017 [acesso em: 27 ago. 2018];12(1):18. Disponível em:

https://doi.org/10.1186/s13011-017-0102-9.

17. Benchaya MC, Bisch NK, Moreira TC, Barros HMT. Non-authoritative parents and impact on drug use: the perception of adolescent children. J Pediatr (Rio J) [Internet]. 2011 [acesso em: 27 ago. 2018];87(3):238-44. Disponível em:

https://doi.org/10.2223/JPED.2089. 
18. Rusnáková M. Codependency of the Members of a Family of an Alcohol Addict. Procedia - Soc Behav Sci [Internet]. 2014 [acesso em: 27 ago. 2018];132:647-53. Disponível em: https://doi.org/10.1016/j.sbspro.2014.04.367.

19. Smith LM, Estegan A. Families Parenting adolescents with substance abuse-recovering the mother's voice. J Fam Nurs [Internet]. 2014 [acesso em: 27 ago. 2018];20(4):415-41. Disponível em: https://doi.org/10.1177/1074840714554397.

20. Teixeira LL, Batalla LS, Oliveira SM, Santos AM, Maagh SB. O cotidiano familiar após a descoberta do filho dependente químico. Rev enferm UFPE on line [Internet]. 2014 [acesso em: 27 ago. 2018];8(supl. 2):3629-46. Disponível em:

https://periodicos.ufpe.br/revistas/revistaenfermagem/article/view/10104/10572.

21. Siqueira DF, Moreschi C, Backes DS, Terra MG, Soccol KLS, Mostardeiro SCTS. Percepção de familiares sobre a iniciação do uso de crack por adolescente. Cienc Cuid Saude [Internet]. 2015 [acesso em: 27 ago. 2018];14(1):948-54. Disponível em:

https://doi.org/10.4025/cienccuidsaude.v14i1.23019.

22. Rodrigues JSM, Ferreira NMLA. Estrutura e funcionalidade da rede de apoio social do adulto com câncer. Acta Paul Enferm [Internet]. 2012 [acesso em: 27 ago. 2018];25(5):781-7. Disponível em: https://doi.org/10.1590/S0103-21002012000500021.

23. Silva PA, Silva MRS, Luz G. Interações protetoras em famílias de alcoolistas: bases para o trabalho de enfermagem. Rev. enferm. UERJ [Internet]. 2012 [acesso em: 27 ago. 2018];20(2):191-6. Disponível em: http://www.epublicacoes.uerj.br/index.php/enfermagemuerj/article/view/4043.

24. Puggina ACG, Silva MJP. Religião/Espiritualidade como estratégia de enfrentamento de familiares de pacientes com desordem de consciência. Revista Saúde [Internet]. 2015 [acesso em: 27 ago. 2018];9(3-4):5-17. Disponível em:

http://revistas.ung.br/index.php/saude/article/view/2136. 